Journal of Economics and Behavioral Studies

Vol. 3, No. 2, pp. 133-144, Aug 2011 (ISSN: 2220-6140)

\title{
Multidimensional Poverty in Pakistan: Case of Punjab Province
}

\author{
Masood Sarwar Awan ${ }^{1}$, *Muhammad Waqas ${ }^{1}$, Muhammad Amir Aslam² \\ ${ }^{1}$ Department of Economics University of Sargodha, Pakistan \\ 2 District Courts Sargodha, Punjab Home Department, Pakistan \\ *economist147@hotmail.com
}

\begin{abstract}
This paper applies Alkire \& Foster (2007) approach for measuring the multidimensional poverty. The data set used in the study is Multiple Indicator Cluster Survey 2003-04 of Punjab, Pakistan. Eight dimensions used in the study are Housing, Water, Sanitation, Electricity, Assets, Education, Expenditure, and Land. Results shows that at cut off K=2; Rajanpur, Muzaffargarh, Rahimyar Khan, Kasur, Okara and Lodhran respectively are the most multidimensionally poor districts of Punjab whereas, Gunj Buksh Town Lahore, Ravi Town Lahore, Cantt Town Lahore, Sialkot, Rawalpindi, Allama Iqbal Town Lahore, Gujranwala and Jhelum are the least deprived Towns/Districts of Punjab province. Dimension wise breakdown shows that Land deprivation, expenditure, sanitation, housing and education are respectively the major contributors among overall multidimensional poverty.
\end{abstract}

Keywords: Multidimensional Poverty, Pakistan, MDGs.

\section{Introduction}

Multidimensional poverty is currently at the heart of many theoretical, empirical and institutional debates. Since the seminal work of Sen, it has been recognized that poverty is a multidimensional phenomenon and the unprecedented availability of relevant data has renewed interest in the multidimensionality of the poverty. In a pioneering contribution, Sen (1976) regarded the poverty measurement as involving two steps: (i) the identification of the poor and (ii) the aggregation of the characteristics of the poor into an overall indicator that quantifies the extent of poverty. Identification typically makes use of an income cutoff called the poverty line and evaluates whether an individual's income achieves this level or not. Planning Commission of Pakistan has been using the following definition for estimating the poverty line. "Calorific requirement approach wherein all those households (or individuals) are classified as poor who do not have income sufficient to allow a consumption pattern consistent with minimum calorie requirements. It is also assumed that the household earning incomes equivalent to poverty line not only have sufficient food to meet the minimum nutrition requirements but also the non-food requirements." (PRSP-II, GOP 2009).

The second step which is involved in the process of measurement of poverty is aggregation and it is typically accomplished by selecting a poverty index or measure. Planning Commission of Pakistan for the purpose of aggregation used the poverty measure suggested by Foster, Greer, and Thorbecke (1984) these are the Headcount ratio, Poverty Gap, and Squared Poverty Gap. Some arguments suggest that now we have to go beyond these money-metric measures and consider other poverty measurements. The first argument relates to the fact that the quality of income/expenditure data is often poor in many developing countries. The reliability and credibility of Pakistan's Poverty data is questionable. In the last decade, the Federal Bureau of Statistics (FBS) has made frequent changes in data collection methods that may have affected the reliability and comparability of survey data. Similarly, different data sources that are not comparable in terms of design, coverage of seasons, or methodology, are often used in many official documents to examine poverty trends. The use of incomparable data has also affected data reliability adversely. The strength of Household Integrated Economic Survey (HIES) as the main data source for poverty estimates in Pakistan, has weakened since the 1990s, when it was merged with the Pakistan Integrated Household Survey (PIHS) (Arif, 2003 2006).

The second argument which is mainly concerned with the theoretical and methodological aspect is about the multidimensionality of well-being. Poverty has many dimensions in Pakistan. The poor have not only low incomes but they also lack access to basic needs such as education, health, clean drinking water and proper 
sanitation. The latter undermines their capabilities, limits their opportunities to secure employment, results in their social exclusion and exposes them to exogenous shocks (PRSP-II). This paper applies Alkire \& Foster (2007) approach for measuring the multidimensional poverty, because it is easy to implement and it integrates the identification analysis using dual cutoffs. The first is the traditional dimension-specific poverty line or cutoff, which identifies whether a person is deprived with respect to that dimension. The second delineates how widely deprived a person must be in order to be considered poor.

The main objective of the paper is to apply the above mentioned methodology to estimate multidimensional poverty in Punjab Province of Pakistan. This study also highlights the importance of each dimension because the beauty of this methodology is that, we find out the effect of each dimension in overall poverty. This study also gives policy guidelines to the policy makers in order to target each dimension in better way. Rest of the paper is organized as follows. Section 2 briefly revises the literature on multidimensional poverty measures. Section 3 presents the methodology and data used in the paper. Section 4 presents the selected dimensions, and deprivation cutoff values. Section 5 presents the estimation results. Finally, section 6 presents conclusion and policy implications.

\section{Literature Review}

The literature on Multidimensional poverty recognizes three broad classes of measures (Deutsch and Silber, 2005); the axiomatic approach to poverty measure, the Fuzzy set approach, and the information theory approach. Tsui (2002) develops an axiomatic framework for multidimensional poverty and derives two relative multidimensional poverty measures, one was the generalization of Chakravarty's (1983) unidimensional class of poverty indices, and other was the generalization of Watt's (1968) poverty index. Bourguignon and Chakravarty (2003) present a distinct family of multidimensional poverty indices; they distinguish two groups of multidimensional poverty, depending on whether they are treating dimensions to be independent or to have some substitutability or complimentarity. They replace the subgroup consistency of Tsui (2002) with separability axiom. They accept both poverty non-decreasing rearrangement and poverty non-increasing rearrangement. For both group of indices they recommend extension of FGT class of indices. Fuzzy set approach in a multidimensional framework was first used by Cerioli and Zani (1990) who drew inspiration from the theory of Fuzzy sets initiated by Zadeh (1965). Cerioli and Zani's original approach was later developed by Sheli and Lemmi (1995) giving origin to the so called Totally Fuzzy and Relative (TFR) approach (Betti et al, 2007). The distance function approach is widely used in Efficiency analysis.

Lovell et al. (1994) were the first who used this for the analysis of household behavior. Information theory was originally developed by engineers in the field of communications. Theil (1967) was probably the first one to apply this theory to economics. One of the basic concepts used in such an approach is the logarithm of a probability (Deutsch \& Silber, 2005). Information theory has been applied in Multidimensional inequality by many researchers for the perspective of Multidimensional Poverty this approach has been used by Miceli (1997) and Massoumi (2007). Still there is no consensus that which poverty measure is best one. For example, which measure could allow better targeting of the poor and suggest more effective poverty reduction policies. One easy solution of this problem is that the measure is considered good which clearly distinguish between rich and poor i.e., which has good identification criteria. Traditionally there are two identification approaches exist in literature, one is union and other is intersection approach. Intersection approach requires persons to be poor in each and every dimension which are to be considered in order to qualify for a person to be multidimensionally poor. This approach is often considered as too constricting and generally produces low estimates of poverty. Second approach is union approach which regards someone who is deprived in a single dimension as poor in multidimensional context. This is generally considered as overly inclusive and may lead to exaggerated estimates of poverty (Alkire \& Foster, 2007).

Alkire \& Foster (2007) proposed a counting approach for measuring the multidimensional poverty. This approach has a number of characteristics that deserve mention. First the identification method mentioned in this approach is poverty focused. Second, it is deprivation focused. Third, this approach can be meaningfully used with ordinal data. Fourth, this approach satisfies several desirable properties including decomposability. Fifth, we can also assign different weights to each dimension. 


\section{Data and Methodology}

The data set used in this study is the Multiple Indicator Cluster Survey (2003-04) of Punjab province. This data set contains sample of 30932 households. The entire sample of households (SSUs) is drawn from 2190 Primary Sampling Units (PSUs) out of which 1163 are urban and 1027 are rural. The sample households have been allocated to 34 districts in proportion to their population according to the 1998 population census, however higher proportion of sample is allocated to the urban domain and to smaller district to get the district estimates with urban and rural breakdown of desired precision.

A two-stage stratified sample design has been adopted for this survey. Sample PSUs from each stratum/substratum have been selected with probability proportional to size. The numbers of households and population have been considered as measure of size pertaining to urban and rural domain respectively. Weight at first stage is an inverse of probability of selection i.e. total measure of size of a stratum divided by measure size of a sample PSU. Based on actual listing undertaking in respect of each sample PSU by the Field Staff 16 and 12 households have been selected from rural and urban sample areas respectively adopting systematic sampling technique with a random start. Households have been considered as secondary sampling units for urban while population has been taken as measure of size in respect to rural areas. Weight at second stage is computed as total listed households in a sample PSU divided by covered household in a sample PSU.

In this paper we use a methodology for multidimensional poverty measurement proposed by Alkire and Foster's (2007). First we define the notations which will be helpful to provide an outline of the measure.

Let $M^{n, d}$ denote the set of all $n \times d$ matrices, and $y \in M^{n_{i} d}$ represents an achievement matrix of $n$ people in $d$ different dimensions. For every $i=1,2, \ldots, n$ and $j=1,2, \ldots, d$, the typical entry $y_{i j}$ of $\mathrm{y}$ is individual $i$ 's achievement in dimension $j$. The row vector $y_{i}=\left(y_{i 1}, y_{i 2}, \ldots y_{i d}\right)$ lists individual $i$ 's achievements and the column vector $y_{j}=\left(y_{j 1}, y_{j 2}, \ldots y_{j d}\right)$ gives the distribution of achievements in dimension $j$ across individuals. Let

$z_{j}>0$ represent the cutoff below which a person is considered to be deprived in dimension $j$ and $\mathrm{z}$ represent the row vector of dimension specific cutoffs. Following Alkire and Foster's (2007)'s notations, any vector or matrix $\mathrm{v},|v|$ denotes the sum of all its elements, whereas $\mu(v)$ is the mean of $v$.

Alkire and Foster (2007) suggest that it is useful to express the data in terms of deprivations rather than achievements. For any matrix $y$, it is possible to define a matrix of deprivations $g^{0}=\left[g_{i j}^{0}\right]$, whose typical element $g_{i j}^{0}$ is defined by $g_{i j}^{0}=1$ when $y_{i j}<z_{j}$, and $g_{i j}^{0}=0$ when $y_{i j} \geq z_{j}, g^{0}$ is an $n \times d$ matrix whose $i j^{\text {th }}$ entry is equal to 1 when person $i$ is deprived in $j$ th dimension, and 0 when person is not. $g_{i}^{0}$ is the $i^{\text {th }}$ row vector of $g^{0}$ which represent person i's deprivation vector. From $g^{0}$ matrix, define a column vector of deprivation counts, whose $i^{\text {th }}$ entry $c_{i}=\left|g_{i}^{0}\right|$ represents the number of deprivations suffered by person $i$. If the variables in $y$ are only ordinally significant, $g^{0}$ and $c$ are still well defined. If the variables in y are cardinal then we have to define a matrix of normalized gaps $g^{1}$. For any y, let $g^{1}=\left[g_{i j}^{1}\right]$ be the matrix of normalized gaps, where the typical element is defined by $g_{i j}^{1}=\left(z_{j}-y_{i j}\right) / z_{j}$ when $y_{i j}<z_{j}$, and $g_{i j}^{1}=0$ otherwise. The entries of this matrix are non-negative numbers less than or equal to 1 , with $g_{i j}^{1}$ being a measure of the extent to which person $i$ is deprived in dimension $j$. This matrix can be generalized to $g^{\propto}=\left[g_{i j}^{\propto}\right]$, with $\alpha>0$, whose typical element $g_{i j}^{\propto}$ is normalized poverty gap raised to the $\alpha$-power.

After defining the notation, now we provide an outline of the class of multidimensional poverty measure suggested by Alkire and Foster (2007). A reasonable starting point is to identify who is poor and who is not? Most of the identification method suggested in the literature normally follows the union or intersection approach. According to the union approach a person $i$ is said to be multidimensionally poor if there is at least one dimension in which the person is deprived, whereas according to intersection approach a person $i$ is said 
to be multidimensionally poor if that person is deprived in all dimensions. If dimensions are equally weighted then the methodology to identify the multidimensionally poor proposed by Alkire and Foster compares the number of deprivations with a cutoff level $k$. where $k=1,2, \ldots, d$. let us define the identification method $\rho_{k}$ such that $\rho_{k}\left(y_{i j} z\right)=1$ when $c_{i} \geq k$, and $\rho_{k}\left(y_{i,} z\right)=0$ when $c_{i}<k$. This means that a person is identified as multidimensionally poor if that person is deprived in at least $k$ dimensions. This is called dual cutoff method of identification because $\rho_{k}$ is dependent on both the within dimension cutoffs $\mathrm{z}_{\mathrm{j}}$ and across dimensions cutoff $k$. This identification criterion defines the set of the multidimensionally poor people as $Z_{k}=\left\{i: \rho_{k}\left(y_{i} ; z\right)=1\right\}$. A censored matrix $g^{0}(k)$ is obtained from $g^{0}$ by replacing the $i^{\text {th }}$ row with a vector of zeros whenever $\rho_{k}\left(y_{i}, z\right)=0$. An analogous matrix $g^{\propto \mathrm{C}}(\mathrm{k})$ is obtained for $\alpha>0$, with the ijth element $g_{i j}^{\propto}(\mathrm{k})=g_{i j}^{\propto}$ if $c_{i} \geq k \& g_{i j}^{\infty}(k)=0$ if $c_{i}<k$.

On the basis of this identification method, Alkire and Foster define the following poverty measures. The first natural measure is the percentage of individuals that are multidimensionally poor: the multidimensional Headcount Ratio $H=H(y ; z)$ is defined by $H=q / n$, where $q=q(y, z)$ is the number of people in set $Z_{k}$. This is entirely analogous to the income headcount ratio. This measure has the advantage of being easily comprehensible and estimable \& this can be applied using ordinal data. However, it suffers from the disadvantages first noticed by Watts (1969) and Sen (1976) in the unidimensional context, namely being insensitive to the depth and distribution of poverty, violating monotonicity and the transfer axiom. Whereas, in the multidimensional context it also violates dimensional monotonicity (Alkire \& Foster, 2007). Alkire and Foster explain this as if a poor person already identified as poor become deprived in an additional dimension (in which this person was not previously deprived), $H$ does not change.

To overcome this problem of multidimensional headcount, Alkire and Foster (2007) propose the dimension adjusted FGT measures, given by $M_{\propto}(y ; z)=\mu\left(g^{\alpha}(k)\right)$ for $\alpha \geq 0$. When $\alpha=0$, the measure is called Adjusted Headcount Ratio, defined by $\mathrm{Mo}=\mu\left(g^{\mathrm{O}}(k)\right)=\mathrm{HA}$, the adjusted headcount ratio is the total number of deprivations experienced by the poor $\left(|c(k)|=\left|g^{0}(k)\right|\right)$, divided by the maximum number of deprivations that could possibly be experienced by all people $(n d)$. It can also be expressed as the product between the percentage of multidimensionally poor individuals $(H)$ and the average deprivation share across the poor, which is given by $A=|c(k)| /(q d)$. In words, A provides the fraction of possible dimensions $d$ in which the average multidimensionally poor individual is deprived. In this way, $M_{0}$ summarizes information on both the incidence of poverty and the average extent of a multidimensionally poor person's deprivation. This measure is easy to compute as $\mathrm{H}$, and can be calculated with ordinal data and it is superior to $\mathrm{H}$ because it satisfies the dimensional monotonicity property.

The class of dimension adjusted FGT measure also yields the Adjusted Poverty Gap, give by $M_{1}=\mu\left(g^{1}(k)\right)=H A G$, which is the sum of the normalized gaps of the poor $\left(\left|g^{1}(k)\right|\right)$ divided by the highest possible sum of the normalized gaps (nd). It can also be expressed as the product between the percentage of multidimensionally poor persons $(H)$, the average deprivation share across the poor $(A)$ and the average poverty gap $(G)$, which is given by $G=\left|g^{1}(k)\right| /\left|g^{0}(k)\right|$. The poverty measure $M_{1}$ ranges in value from 0 to 1 . If the dimension of poor person deepens in any dimension, then the respective $g^{1}(k)$ will rise and hence so will $M_{1}$. Consequently $M_{1}$ satisfies monotonicity.

Finally, when $\alpha=2$, the measure is the Adjusted Poverty Gap, and it is represented by $M_{2}$ \& $M_{2}=\mu\left(g^{2}(k)\right)=$ HAS, which is the sum of the squared normalized gaps of the poor $\left(\left|g^{2}(k)\right|\right)$ divided by the highest possible sum of the normalized gaps $(n d)$. It can also be expressed as the product between the percentage of multidimensionally poor persons $(H)$, the average deprivation share across the poor $(A)$ and the average severity of deprivations (S), which is given by $S=\left|g^{2}(k)\right| /\left|g^{0}(k)\right| . M_{2}$ summarizes information on the incidence of poverty, the average range and severity of deprivations and the average depth of deprivations of the poor. If a poor person becomes deprived in a certain dimension, $M_{2}$ will increase 
more the larger the initial level of deprivation was for this individual in this dimension. This measure satisfies both types of monotonicity and also transfer, being sensitive to the inequality of deprivations among the poor as it emphasizes the deprivations of the poorest.

All members of the $M_{\propto}(y ; z)$ family are decomposable by population subgroups. Given two distributions $\mathrm{x}$ and $y$, corresponding to two population subgroups of size $n(x)$ and $n(y)$ correspondingly, the weighted average of sum of the subgroup poverty levels (weights being the population shares) equals the overall poverty level obtained when the two subgroups are merged:

$$
M\left(x_{y}, y_{y} z\right)=\frac{n(x)}{n(x y)} M(x, y)+\frac{n(x)}{n(x y)} M(x, z)
$$

All members of the $M_{\propto}(y ; z)$ family can also be broken down into dimension subgroups. To see this, note that the measures can be expressed in the following way:

$M_{\propto c}\left(y_{s} z\right)=\sum_{j=1}^{n} \mu\left(g_{s j}^{\infty}(k)\right) / d$, where $g_{8 j}^{\propto}$ is the $j^{\text {th }}$ column of the censored matrix $g^{\propto}(k)$. Strictly speaking, this is not decomposability in terms of dimensions, since the information on all dimensions is needed to identify the multidimensionally poor. However, Once the identification step has been completed, and the non-poor rows of $g^{\propto c}$ have been censored to obtain $g^{\propto}(k)$ the above aggregation formula shows that overall poverty is the average of the $d$ many dimensional values $\mu\left(g_{s j}^{\alpha}(k)\right)$. Consequently, $\left(\mu\left(g_{s j}^{\alpha}(k) / d / M_{\alpha}\left(y_{x} z\right)\right.\right.$ can be interpreted as the contribution of dimension $j$ to overall multidimensional poverty.

The $M_{\propto}\left(y_{z} z\right)$ family adopts the neutral assumption of considering dimensions as independent. In this way, it satisfies a property, based on Atkinson and Bourguignon (1982), called weak rearrangement. The concept is based on a different sort of 'averaging' across two poor persons, whereby one person begins with weakly more of each achievement than a second person, but then switches one or more achievement levels with the second person so that this ranking no longer holds. In other words, we can say that a simple rearrangement among the poor reallocates the achievements of two poor persons but leaves the achievements of everyone else unchanged. This is called an association decreasing rearrangement. Under such rearrangement one would expect multidimensional poverty not to increase. This is postulated by the weak rearrangement axiom and it is precisely satisfied by the $M_{\alpha}\left(y_{x} z\right)$, which will not change under such transformation. Because of its completely additive form, it evaluates each individual's achievements in each dimension independently of the achievements in the other dimensions of other's achievements. We use same weights for all dimensions but this $M_{\varpi}\left(y_{s} z\right)$ family can be extended into a more general form, admitting different weighting structures.

\section{Selected Dimensions and Deprivation Cut-Offs}

This section presents the dimensions, indicators and cutoffs for each dimension in this study. The index is based on the idea that lack of different capabilities gives rise to multiple deprivations. Each capability illustrates the aspects of these deprivations. However, the indicators have been selected exclusively on the basis of availability of data in the MICS 2003-04. All the dimensions are weighted equally. However, the weights are flexible enough to be adjusted according to the ground realities. The selected dimensions and their cut-offs are illustrated below.

Deprivation in Housing: This dimension identifies households living in deficient and pathetic housing structures. It is represented by number of persons in one room. For this purpose a variable person per room is derived by dividing number of persons in household by number of rooms for that particular household. The household is considered to be deprived in housing if three or more persons are sharing one room.

Deprivation in Water: The deprivation in water demonstrates the households with lack of access to clean drinking water. Improved drinking water sources are defined in terms of the type of technology and level of services that are more likely to provide safe water than unimproved technologies. Following the recommendations of WHO that because of the difficulties in measuring safe water, improved sources be used 
as a proxy. The access to clean drinking water is treated as inadequate if the water sources are from: Unprotected dug well, unprotected pond, river canal or stream, vendor provided, tanker truck provision, bottled and other. Or household is not using from these resources: piped water, public standpipe or tap, hand pump, donkey pump/turbine, protected dug well and protected pond.

Deprivation in Sanitation: Access to improved sanitation is a fundamental need and a human right essential for the dignity and health of all people. The dimension discriminates proportion of households lacking the hygienic sanitation facilities. Household is considered to be deprived in sanitation if using from any of these sources: service or bucket latrine (where excreta are manually removed), open-air latrine (in compound), public latrine and open places.

Deprivation in Electricity: Access to basic utilities is a central part of people's daily life. There are many other utilities available in the questionnaire but this study considers only availability of electricity connection as a dimension of poverty. Deprivation for this dimension includes households with no electricity.

Deprivation in Assets: Next dimension used in this study is about the possession of some listed assets. A household is said to be deprived in assets if do not own anything form these items: air conditioner, air cooler or fan, cooking range or freezer, washing machine or dryer, sewing machine or knitting machine, radio, television, bicycle, motorcycle or scooter, car or other vehicle, personal computer, water pump/turbine, any other.

Deprivation in Education: Education is another dimension used in this study and the question is about literacy of each household member. If there is no literate person in the household, it is considered to be deprived in education.

Deprivation in Expenditure: Expenditure is an important measure of well-being in developing countries. Most of developed countries used income as a measure of well-being where as most developing countries used expenditure. Major reasons for not using income as a measure of well-being in developing countries are likely to be underreported, may be affected by short-term fluctuation, some part of income are hard to observe e.g., informal sector income, self-employment income etc. another important criticism on income is that the link between income and welfare in not always clear, and reporting period might not capture the average income of the household. Expenditure shows current actual material standard of living, smoothes out irregularities and so reflects long-term average well-being. Another important reason for using expenditure in developing countries is that is less understated than income because expenditure is easier to recall (Albert, 2004; Handbook of poverty + inequality). Household is supposed to be deprived in expenditure if its per capita monthly expenditures are less than Rs. 807.53 (poverty line 2003-04).

Deprivation in Land: Another dimension used in this study is the possession of land. It may be a house(s), any other urban property or irrigated/non-irrigated/and un-cultivated land. If the monetary value of total land property is less than Rs. 3,00,000, the household is concluded to be deprived in land possession 1 .

\section{Results and Discussion}

Multidimensional Poverty calculated for Punjab on the basis of different variables. These include variables such as Expenditure, Education, Housing, Drinking Water, Sanitation, Electricity and Asset. Results shows that at cut off K=2; Rajanpur, Muzaffargarh, Rahimyar Khan, Kasur, Okara and Lodhran respectively are the most multidimensionally poor districts of Punjab whereas, Gunj Buksh Town Lahore, Ravi Town Lahore, Cantt Town Lahore, Sialkot, Rawalpindi, Allama Iqbal Town Lahore, Gujranwala and Jhelum are the least deprived Towns/Districts of Punjab province (For more detail see Appendix Table $1 \& 2$ and Figures 1-9).

\footnotetext{
${ }^{1}$ Different worthy Economists of Pakistan have been conversed regarding the cut-off for land possessions
} 
Figure 5.1: Spatial Distribution

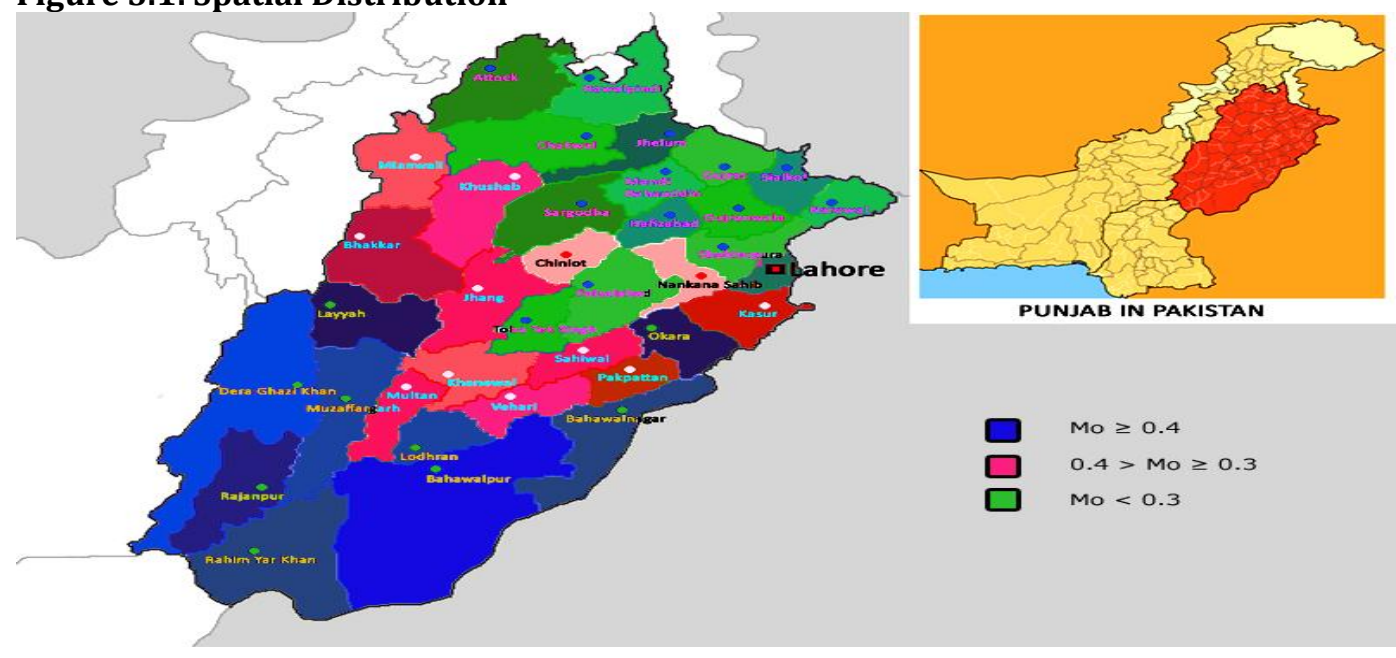

The districts marked as poorest in income/consumption poverty criterion are not always the identical as regions identified as poorest in multidimensional perspective. This might be equally due to both averaging out between better and worse performing districts comprising a region, and also the addition of variables reflecting non-income measures of development through including capabilities such as being literate etc. Detection of districts that are evidence for chronic deprivation in multidimensional paradigm is the first step in determining strategies to correct such imbalances.

Contribution of Each Dimension: MPI is a high-resolution lens: you can zoom in and see more allowing one to grasp beyond whether someone is poor, but precisely how she is poor" (Alkire \& Foster, 2007).

Figure 5.2: Contribution of each dimension at $\mathrm{K}=2$.

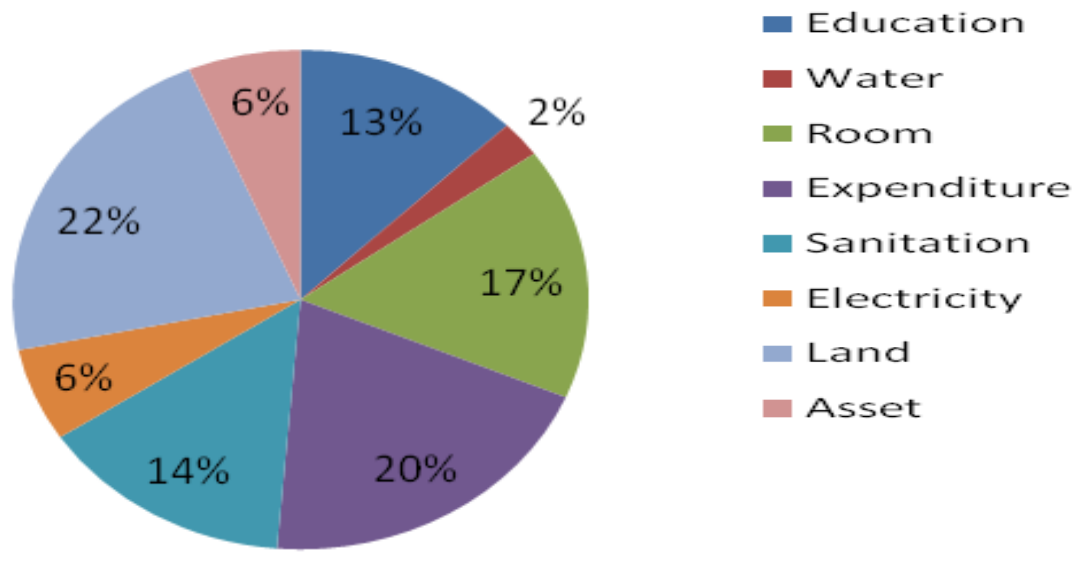

Source: Authors own calculations

Dimension wise break down shows that Lack of Land resources, Low level of expenditures contribute, Sanitation, Number of bedrooms available per person and education also have a significant share in multidimensional poverty. (For more detail see Appendix Table 3)

\section{Conclusion and Policy Implications}

The paper established a robust measurement of multidimensional poverty using data from Multiple Indicator Cluster Survey (2003-04) of Punjab province. By employing the Alkire \& Foster (2007) approach for measuring the multidimensional poverty the study highlights that at cut off $\mathrm{K}=2$; Rajanpur, Muzaffargarh, Rahimyar Khan, Kasur, Okara and Lodhran respectively are the most multidimensionally poor districts of 
Punjab whereas, Gunj Buksh Town Lahore, Ravi Town Lahore, Cantt Town Lahore, Sialkot, Rawalpindi, Allama Iqbal Town Lahore, Gujranwala and Jhelum are the least deprived Towns/Districts of Punjab province.

Dimension wise analysis shows that Lack of Land resources and Low level of expenditures contribute $42 \%$ to the multidimensional poverty in Punjab. Further more, Sanitation and Number of bedrooms available per person contributes $31 \%$ of total Poverty. It shows that a great number of large families are living in small houses that either do not have proper sanitation facility or share toilets. On account of findings, the prime policy inference from the study is to employ multidimensional poverty as one of the criterion in the allocation of fiscal resources from the centre to the state. Giving a reasonable proportion to poverty in the criterion of resource allocation in current NFC award is a step towards the process. Given the administrative structure at district and tehsil level and multiplicity in socio economic development in Punjab, and even all provinces of Pakistan, along with provincial level, this exercise must be practiced at district and even tehsil level. Finally, it is recommended that some serious protective measures to combat poverty should be taken in the most deprived areas of Sothern Punjab, and mostly in terms of land resources, and sanitation for the abject poor, irrespective of caste, belief, and political affiliation so as to address the equality issues to comprehend the MDGs.

\section{References}

Alkire, S., \& Foster, J. (2007). Counting and Multidimensional Poverty Measures. OPHI working paper series, (7).

Arif, G. M. (2003). Poverty Dynamics in Pakistan: Evidence from the Two Panel Household Survey. Pakistan Human Condition Report 2003. Islamabad: CRPRID.

Arif, G. M. (2006). Poverty, Economic Growth, and Inequality: A Review of Pakistan's Poverty Literature. Background Paper prepared for Asian Development Bank.

Atkinson, A. B., \& Bourguignon, F. (1982). The comparison of multi-dimensional distribution of economic status. The Review of Economic Studies, 49(2), 183-201.

Betti G., Cheli B., Lemmi A. \& Verma V. (2007). The Fuzzy Approach to Multidimensional Poverty: the Case of Italy in the 1990s, in Kakwani N. and Silber J. (eds.), Quantitative Approaches to Multidimensional Poverty Measurement, Palgrave Macmillan, 30-48.

Bourguignon, F., \& Chakravarty, S. R. (2003). The measurement of multidimensional poverty. Journal of Economic Inequality, 1(1), 25-49.

Cerioli, A. \& Zani, S. (1990). A Fuzzy Approach to Measurement of Poverty, in C. Dagum and M. Zenga (eds), Income and wealth distribution, inequality and poverty: studies in contemporary economics. Berlin: Springer Verlag, 272-84.

Chakravarty, S. R. (1983). A new index of poverty. Mathematical Social Sciences, 6(3), 307-313.

Deutsch, J. \& Silber, J. (2005). Measuring Multidimensional Poverty: An Empirical Comparison of Various Approaches. The Review of Income and Wealth, 51(1), 145-174.

Federal Bureau of Statistics (FBS). (2006). Pakistan Social and Living standard Measurement Survey 2005-06, Islamabad: Government of Pakistan.

Foster, J. E., Greer, J. \& Thorbecke, E. (1984). A Class of Decomposable Poverty Indices. Econometrica, 52(1), 761-766.

Government of Pakistan. (2008). Poverty Reduction Strategy Paper II. http://www.finance.gov.pk.

Lovell, C. A. K., Richardson, S., Travers, P., \& Wood, L. (1994). Resources and Functioning: A New View of Inequality in Australia, in: Eichhorn, W. (ed.), Models and Measurement of Welfare and Inequality, Springer-Verlag, Heidelberg, 1994.

Massoumi, E. \& Lugo, M. A. (2007). The information basis of multivariate poverty assessments', in (N. Kakwani and J. Silber, eds.), The Many Dimensions of Poverty, Palgrave-MacMillan.

Malik, S. J. (2005). Agricultural Growth and Rural Poverty: A Review of the Evidence. Pakistan Resident Mission Working Paper No. 2. Islamabad: ADB.

Miceli, D. (1997). Mesure de la pauvreté. Théorie et Application à la Suisse. Thèse de doctorat ès sciences économiques et sociale, Université de Genève.

Sen, A. K. (1976). Poverty: An ordinal approach to measurement. Econometrica, 44(2), 219-231. 
Sen, A. K. (1976). Development as freedom (1st edn.; New York: Knopf Press).

Theil, H. (1967). Economics and Information Theory. Amsterdam: North Holland.

Tsui, K. (1999), Multidimensional Inequality and Multidimensional Generalized Entropy Measures: An Axiomatic Approach. Social Choice \& Welfare, 16(1) 145-157.

Tsui, K. (2002). Multidimensional poverty indices. Social Choice \& Welfare, 19(1), 69-93.

Watts, H. W. (1969). An Economic Definition of Poverty, in D. P. Moynihan (ed.), On Understanding Poverty, New York: Basic Books.

Zadeh, L. A. (1965). Fuzzy sets. Information and Control, 8,338-353.

\section{Appendix}

Figure 1: Multidimensional Adjusted Headcount Ratio (Mo): Contribution of each dimension at different K=1

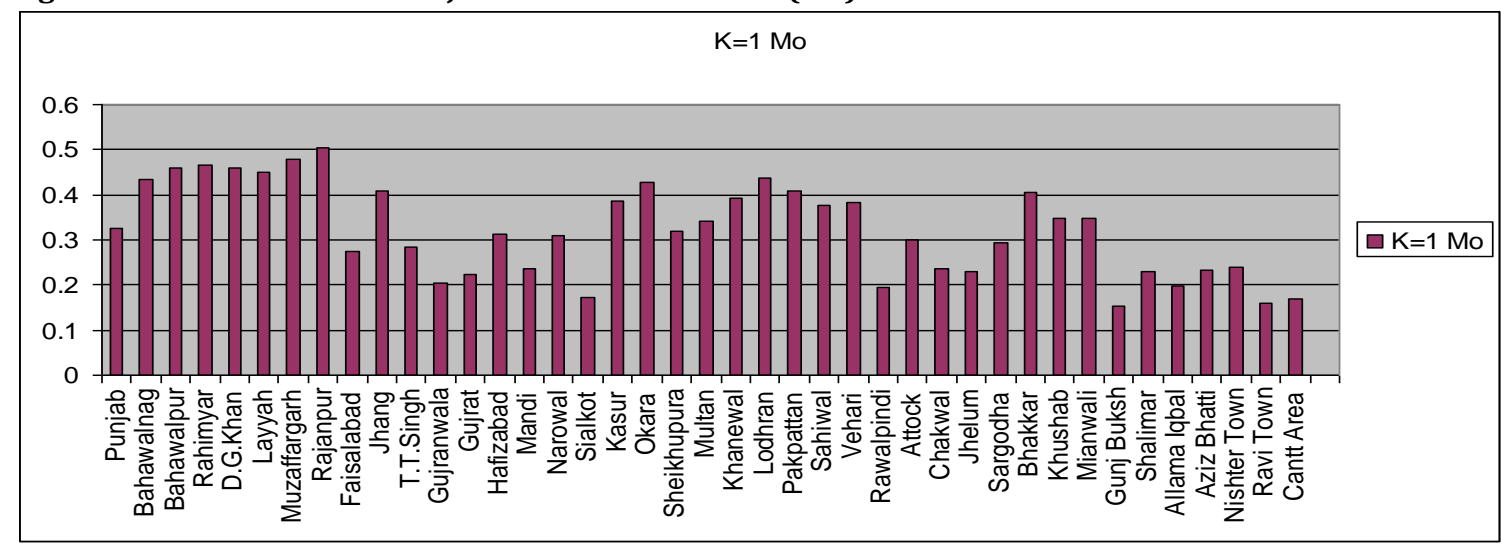

Figure 2: Multidimensional Adjusted Headcount Ratio (Mo): Contribution of each dimension at different K=2

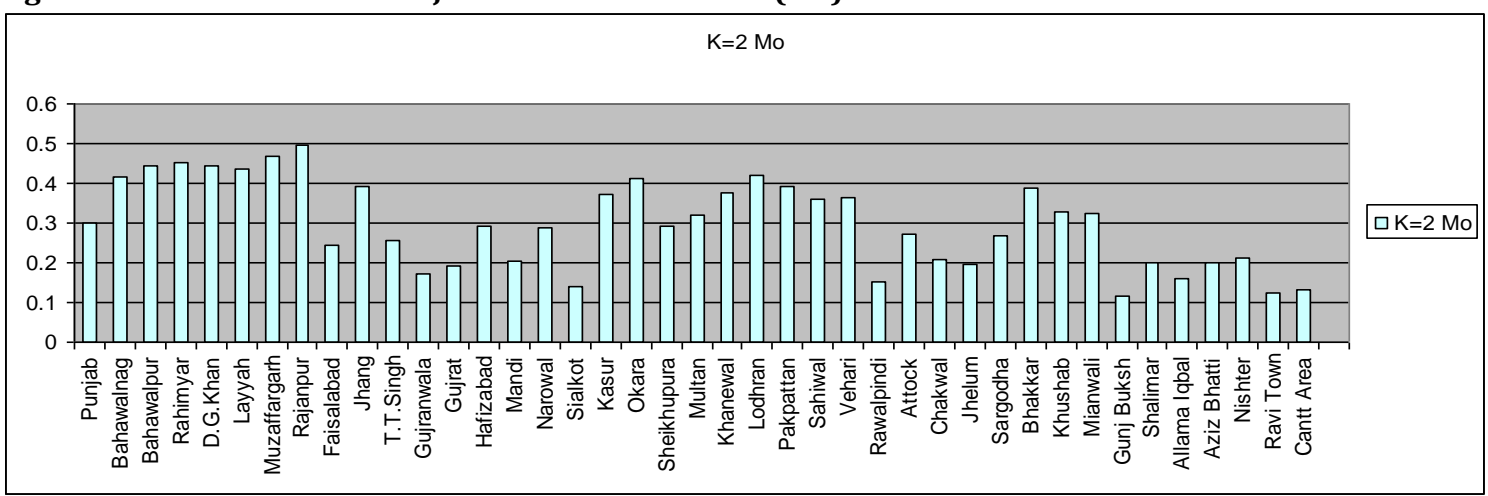

Figure 3: Multidimensional Adjusted Headcount Ratio (Mo): Contribution of each dimension at different K=3

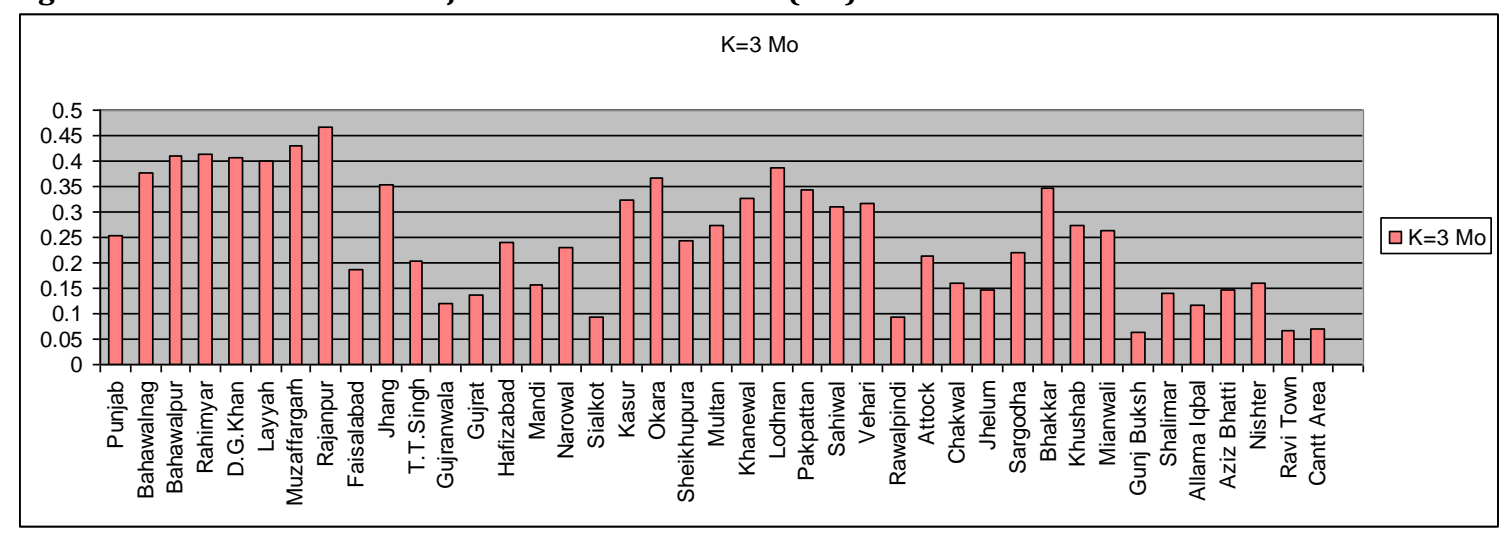


Figure 4: Multidimensional Adjusted Headcount Ratio (Mo): Contribution of each dimension at different K=4

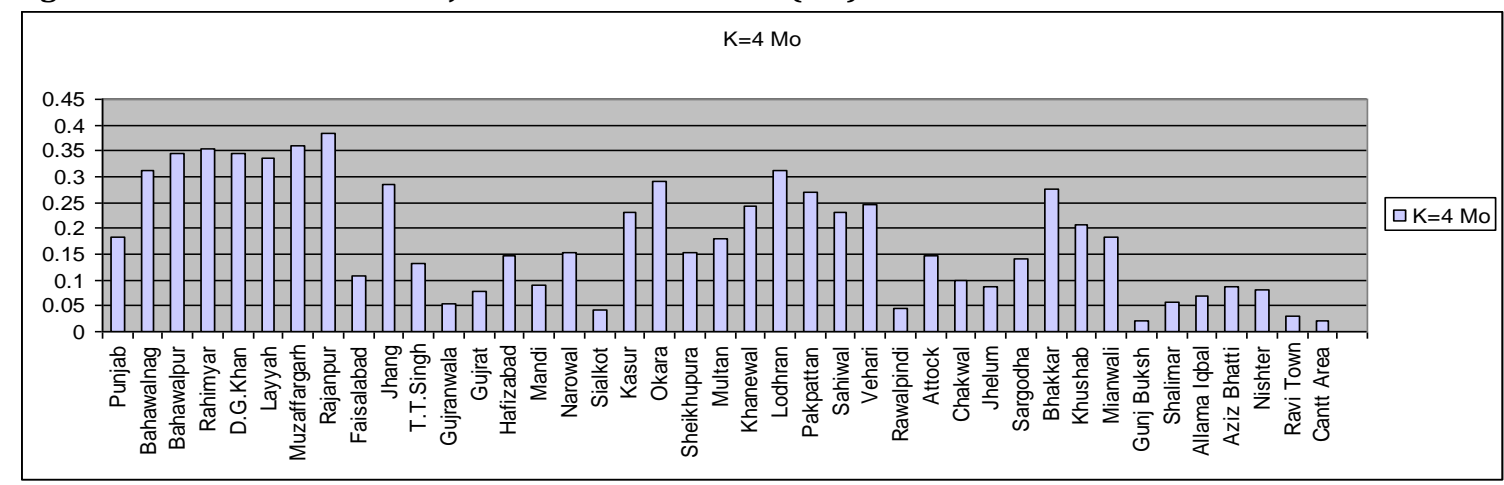

Figure 5: Multidimensional Adjusted Headcount Ratio (Mo): Contribution of each dimension at different K=5

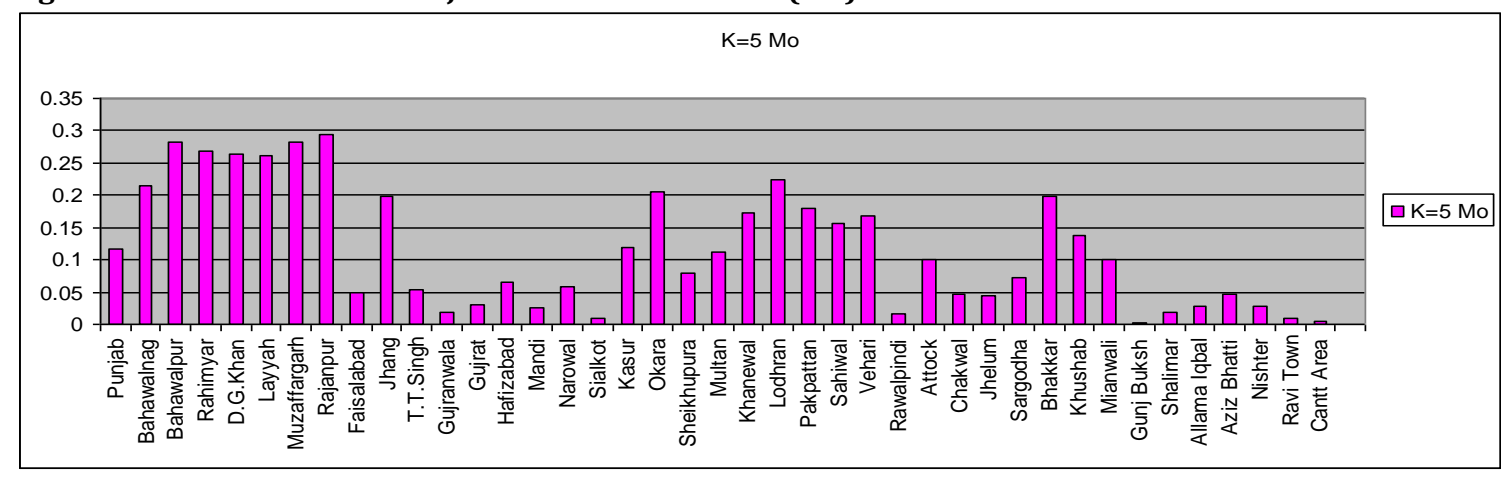

Figure 6: Multidimensional Adjusted Headcount Ratio (Mo): Contribution of each dimension at different K=6

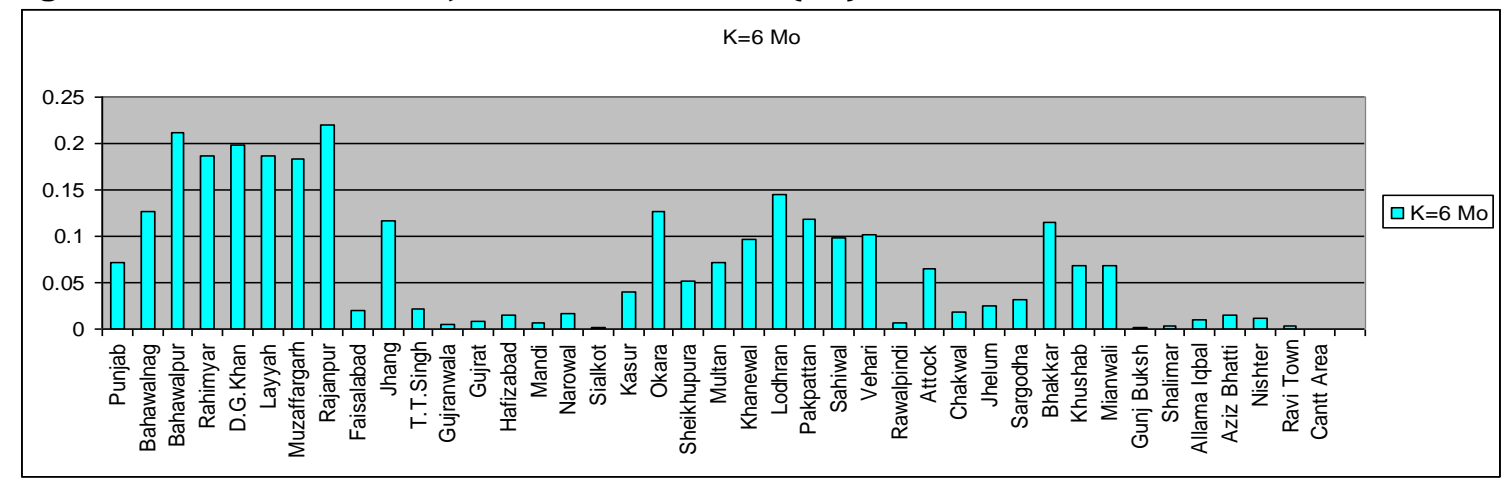

Figure 7: Multidimensional Adjusted Headcount Ratio (Mo): Contribution of each dimension at different $\mathrm{K}=7$

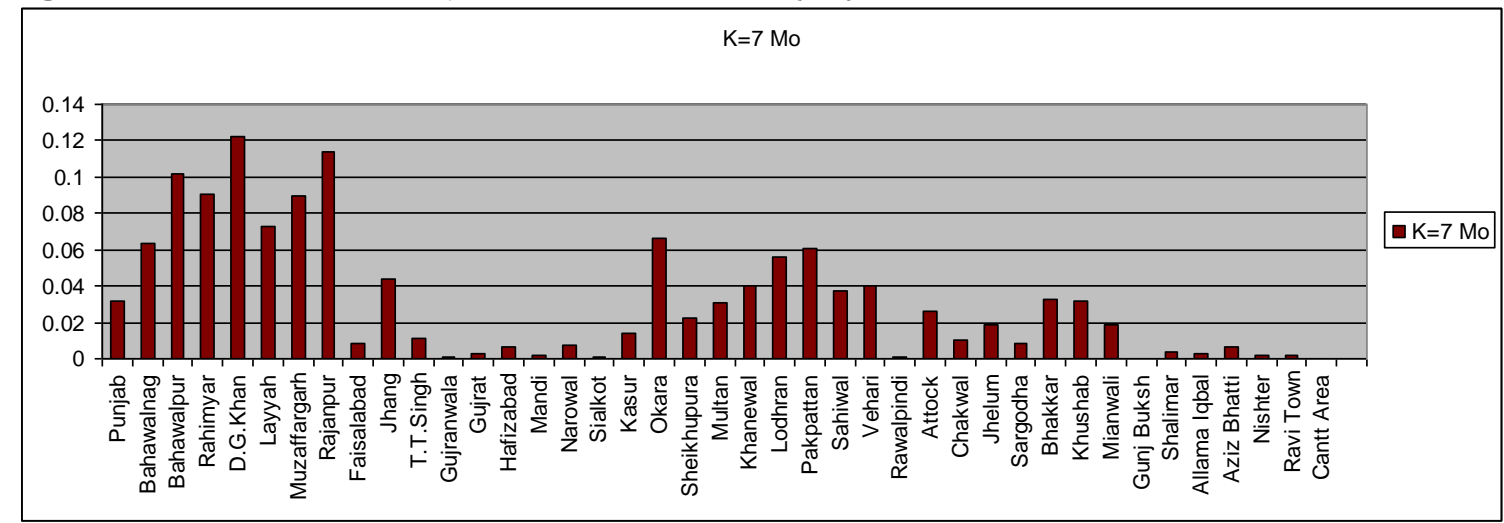


Figure 8: Multidimensional Adjusted Headcount Ratio (Mo): Contribution of each dimension at different K=8

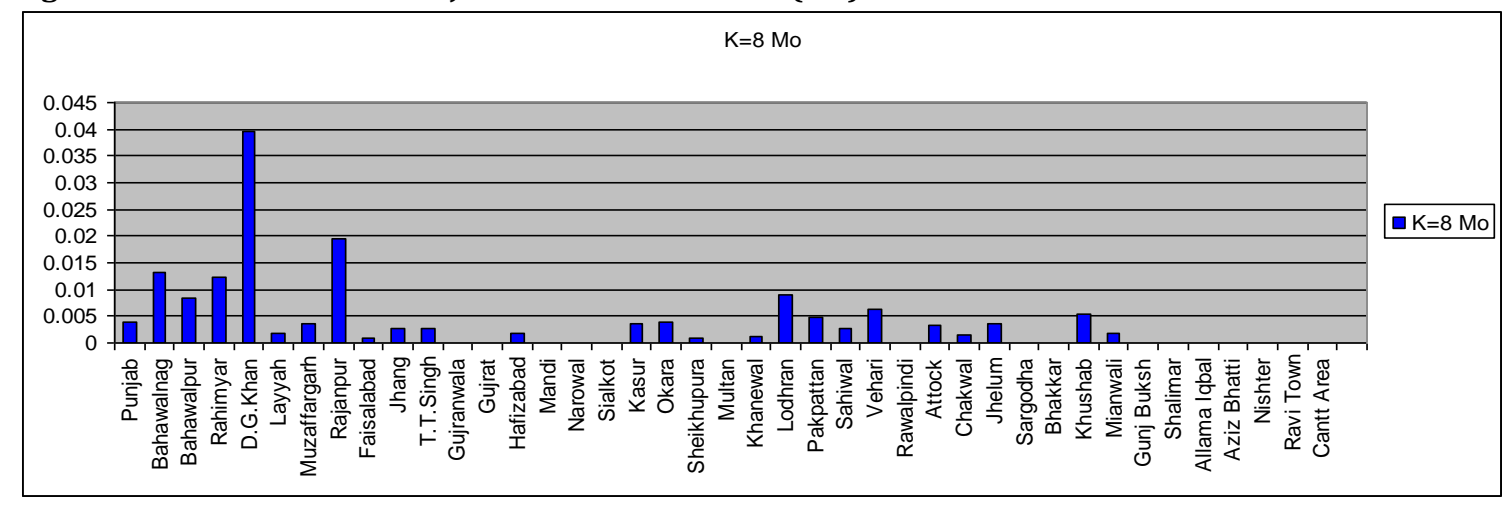

Table 1: Multidimensional Headcount at Different Cut-offs (H)

\begin{tabular}{|c|c|c|c|c|c|c|c|c|}
\hline Area & $\mathrm{K}=1$ & $\mathrm{~K}=2$ & $\mathrm{~K}=3$ & $\mathrm{~K}=4$ & $\mathrm{~K}=5$ & $\mathrm{~K}=6$ & $\mathrm{~K}=7$ & $\mathrm{~K}=8$ \\
\hline Punjab (Overall) & 0.8638 & 0.6739 & 0.4802 & 0.2931 & 0.1618 & 0.0882 & 0.0361 & 0.0038 \\
\hline Bahawalnagar & 0.9606 & 0.8186 & 0.658711 & 0.48926 & 0.297136 & 0.1551313 & 0.0704057 & 0.0131265 \\
\hline Bahawalpur & 0.9301 & 0.8149 & 0.674221 & 0.502361 & 0.374882 & 0.2615675 & 0.115203 & 0.0084986 \\
\hline Rahimyarkhan & 0.9481 & 0.8432 & 0.692464 & 0.529532 & 0.360489 & 0.2291242 & 0.101833 & 0.01222 \\
\hline D.G.Khan & 0.9407 & 0.8107 & 0.668079 & 0.501412 & 0.341808 & 0.2358757 & 0.1341808 & 0.039548 \\
\hline Layyah & 0.9259 & 0.8204 & 0.67037 & 0.505556 & 0.353704 & 0.2351852 & 0.0833333 & 0.0018519 \\
\hline Muzaffargarh & 0.9564 & 0.8792 & 0.726027 & 0.541719 & 0.384807 & 0.2266501 & 0.1021171 & 0.003736 \\
\hline Rajanpur & 0.9673 & 0.9020 & 0.792484 & 0.56536 & 0.385621 & 0.2696078 & 0.127451 & 0.0196078 \\
\hline Faisalabad & 0.8612 & 0.6360 & 0.396405 & 0.189715 & 0.070894 & 0.0249626 & 0.0089865 & 0.0009985 \\
\hline Jhang & 0.9232 & 0.7886 & 0.635071 & 0.448341 & 0.277725 & 0.1459716 & 0.0492891 & 0.0028436 \\
\hline T.T.Singh & 0.8546 & 0.6420 & 0.427995 & 0.234186 & 0.076716 & 0.025572 & 0.0121131 & 0.0026918 \\
\hline Gujranwala & 0.7424 & 0.4848 & 0.27512 & 0.100479 & 0.026316 & 0.007177 & 0.0015949 & 0 \\
\hline Gujrat & 0.7695 & 0.5135 & 0.29303 & 0.142248 & 0.046942 & 0.0099573 & 0.002845 & 0 \\
\hline Hafizabad & 0.8953 & 0.7128 & 0.512411 & 0.264184 & 0.101064 & 0.0177305 & 0.0070922 & 0.001773 \\
\hline Mandi & 0.7816 & 0.5386 & 0.34647 & 0.16913 & 0.037767 & 0.0082102 & 0.001642 & 0 \\
\hline \multicolumn{9}{|l|}{ Bahawaldin } \\
\hline Narowal & .8869 & 0.7065 & 0.486885 & 0.273771 & 0.088525 & 0.0213115 & 0.0081967 & 0 \\
\hline Sialkot & 0.6772 & 0.4029 & 0.213318 & 0.077878 & 0.013544 & 0.0022573 & 0.0011287 & 0 \\
\hline Kasur & .9501 & 0.8387 & 0.648492 & 0.401392 & 0.175174 & 0.049884 & 0.0150812 & 0.0034803 \\
\hline Okara & 0.9550 & 0.8358 & 0.65298 & 0.455629 & 0.282119 & 0.1549669 & 0.0754967 & 0.0039735 \\
\hline Sheikhupura & 0.8930 & 0.6981 & 0.494107 & 0.259293 & 0.107888 & 0.0643699 & 0.0253853 & 0.0009066 \\
\hline Multan & 0.8931 & 0.7316 & 0.541568 & 0.29137 & 0.152811 & 0.0886778 & 0.0348377 & 0 \\
\hline Khanewal & .9340 & 0.8072 & 0.603234 & 0.384328 & 0.243781 & 0.1218905 & 0.0460199 & 0.0012438 \\
\hline Lodhran & 0.9411 & 0.8250 & 0.682143 & 0.482143 & 0.307143 & 0.1803571 & 0.0625 & 0.0089286 \\
\hline Pakpattan & 0.9459 & 0.8197 & 0.618033 & 0.422951 & 0.244262 & 0.1459016 & 0.0688525 & 0.004918 \\
\hline Sahiwal & .9218 & 0.7695 & 0.576159 & 0.366887 & 0.217219 & 0.1231788 & 0.0423841 & 0.002649 \\
\hline Vehari & .9142 & 0.7699 & 0.580846 & 0.38806 & 0.232587 & 0.1281095 & 0.0447761 & 0.0062189 \\
\hline Rawalpindi & 0.7794 & 0.4485 & 0.213235 & 0.079412 & 0.024265 & 0.0095588 & 0.0014706 & 0 \\
\hline Attock & 0.8735 & 0.6371 & 0.403941 & 0.231527 & 0.139573 & 0.0804598 & 0.0295567 & 0.0032841 \\
\hline Chakwal & 0.7467 & 0.5294 & 0.334967 & 0.174837 & 0.066994 & 0.0228758 & 0.0114379 & 0.001634 \\
\hline Jhelum & 0.7744 & 0.4991 & 0.305506 & 0.143872 & 0.060391 & 0.0301954 & 0.0213144 & 0.0035524 \\
\hline Sargodha & 0.8645 & 0.6480 & 0.452977 & 0.240725 & 0.1044 & 0.0396894 & 0.0094909 & 0 \\
\hline Bhakkar & 0.9447 & 0.7861 & 0.620321 & 0.438503 & 0.279857 & 0.1479501 & 0.0374332 & 0 \\
\hline Khushab & 0.8918 & 0.7287 & 0.508865 & 0.33156 & 0.193262 & 0.0851064 & 0.035461 & 0.0053191 \\
\hline Mianwali & 0.9316 & 0.7662 & 0.519784 & 0.303957 & 0.140288 & 0.0863309 & 0.0215827 & 0.0017986 \\
\hline Gunj Buksh Town & 0.6752 & 0.3633 & 0.152294 & 0.038532 & 0.001835 & 0.0018349 & 0 & 0 \\
\hline Shalimar Town & 0.8074 & 0.5631 & 0.325052 & 0.10559 & 0.026915 & 0.0041408 & 0.0041408 & 0 \\
\hline $\begin{array}{l}\text { Allama Iqbal } \\
\text { Town }\end{array}$ & 0.7186 & 0.4283 & 0.25448 & 0.125448 & 0.041219 & 0.0125448 & 0.0035842 & 0 \\
\hline AzizBhatti Town & 0.7895 & 0.5237 & 0.313158 & 0.15 & 0.068421 & 0.0184211 & 0.0078947 & 0 \\
\hline Nishtar Town & 0.7797 & 0.5594 & 0.354776 & 0.148148 & 0.042885 & 0.0155945 & 0.0019493 & 0 \\
\hline Ravi Town & 0.6749 & 0.3843 & 0.154876 & 0.055449 & 0.013384 & 0.0038241 & 0.001912 & 0 \\
\hline Cantt Town & 0.7143 & 0.4146 & 0.174216 & 0.041812 & 0.006969 & 0 & 0 & 0 \\
\hline
\end{tabular}


Table 2: Adjusted Multidimensional Headcount at Different Cut-Offs (Mo)

\begin{tabular}{|c|c|c|c|c|c|c|c|c|}
\hline Area & $\mathrm{K}=1$ & $\mathrm{~K}=2$ & $\mathrm{~K}=3$ & $\mathrm{~K}=4$ & $\mathrm{~K}=5$ & $\mathrm{~K}=6$ & $\mathrm{~K}=7$ & $\mathrm{~K}=8$ \\
\hline $\begin{array}{l}\text { Punjab } \\
\text { (Overall) }\end{array}$ & 0.325131 & 0.301393 & 0.252975 & 0.18281 & 0.117169 & 0.0711644 & 0.032077 & 0.0037714 \\
\hline Bahawalnagar & 0.432876 & 0.415125 & 0.375149 & 0.311605 & 0.215543 & 0.12679 & 0.0632458 & 0.0131265 \\
\hline Bahawalpur & 0.460222 & 0.445822 & 0.410647 & 0.346199 & 0.28246 & 0.2116383 & 0.101865 & 0.0084986 \\
\hline Rahimyarkhan & 0.464613 & 0.451502 & 0.413824 & 0.352724 & 0.268203 & 0.1860998 & 0.0906314 & 0.01222 \\
\hline D.G.Khan & 0.45904 & 0.442797 & 0.407133 & 0.344633 & 0.264831 & 0.1986229 & 0.1223517 & 0.039548 \\
\hline Layyah & 0.449537 & 0.436343 & 0.398843 & 0.337037 & 0.261111 & 0.187037 & 0.0731481 & 0.0018519 \\
\hline Muzaffargarh & 0.477584 & 0.467933 & 0.429639 & 0.360523 & 0.282067 & 0.1832192 & 0.0898194 & 0.003736 \\
\hline Rajanpur & 0.503677 & 0.495507 & 0.468137 & 0.382966 & 0.293096 & 0.2205882 & 0.1139706 & 0.0196078 \\
\hline Faisalabad & 0.273652 & 0.245507 & 0.185597 & 0.108088 & 0.048677 & 0.01997 & 0.007988 & 0.0009985 \\
\hline Jhang & 0.408886 & 0.392062 & 0.353673 & 0.283649 & 0.198341 & 0.1159953 & 0.0434834 & 0.0028436 \\
\hline T.T.Singh & 0.284489 & 0.257907 & 0.204408 & 0.13173 & 0.052995 & 0.0210296 & 0.0109354 & 0.0026918 \\
\hline Gujranwala & 0.204745 & 0.172548 & 0.120116 & 0.054625 & 0.017544 & 0.0055821 & 0.0013955 & 0 \\
\hline Gujrat & 0.222262 & 0.190256 & 0.135135 & 0.078592 & 0.030939 & 0.0078236 & 0.0024893 & 0 \\
\hline Hafizabad & 0.314051 & 0.291223 & 0.241135 & 0.14805 & 0.066489 & 0.014406 & 0.0064273 & 0.001773 \\
\hline Mandi Bahawaldin & 0.235427 & 0.205049 & 0.15702 & 0.090517 & 0.024836 & 0.0063629 & 0.0014368 & 0 \\
\hline Narowal & 0.309016 & 0.286475 & 0.231557 & 0.151639 & 0.059016 & 0.0170082 & 0.0071721 & 0 \\
\hline Sialkot & 0.173533 & 0.139249 & 0.091845 & 0.041055 & 0.008888 & 0.0018341 & 0.0009876 & 0 \\
\hline Kasur & 0.385296 & 0.371375 & 0.323811 & 0.231149 & 0.118039 & 0.0397332 & 0.0136311 & 0.0034803 \\
\hline Okara & 0.426987 & 0.412086 & 0.366391 & 0.292384 & 0.205629 & 0.1261589 & 0.0665563 & 0.0039735 \\
\hline Sheikhupura & 0.317883 & 0.293518 & 0.24252 & 0.154465 & 0.078763 & 0.0515639 & 0.0223255 & 0.0009066 \\
\hline Multan & 0.341746 & 0.321556 & 0.27405 & 0.180226 & 0.110946 & 0.070863 & 0.030483 & 0 \\
\hline Khanewal & 0.392724 & 0.376866 & 0.325871 & 0.243781 & 0.173508 & 0.0973259 & 0.0404229 & 0.0012438 \\
\hline Lodhran & 0.436161 & 0.421652 & 0.385938 & 0.310938 & 0.223438 & 0.1441964 & 0.0558036 & 0.0089286 \\
\hline Pakpattan & 0.408812 & 0.393033 & 0.342623 & 0.269467 & 0.180123 & 0.1186475 & 0.0608607 & 0.004918 \\
\hline Sahiwal & 0.377483 & 0.358444 & 0.310099 & 0.231623 & 0.156788 & 0.0980132 & 0.0374172 & 0.002649 \\
\hline Vehari & 0.383085 & 0.36505 & 0.317786 & 0.245491 & 0.167755 & 0.1024565 & 0.0399565 & 0.0062189 \\
\hline Rawalpindi & 0.194485 & 0.153125 & 0.094302 & 0.044118 & 0.016544 & 0.0073529 & 0.0012868 & 0 \\
\hline Attock & 0.299877 & 0.27032 & 0.212028 & 0.147373 & 0.101396 & 0.0644499 & 0.0262726 & 0.0032841 \\
\hline Chakwal & 0.236111 & 0.208946 & 0.160335 & 0.100286 & 0.046364 & 0.0187908 & 0.0102124 & 0.001634 \\
\hline Jhelum & 0.229796 & 0.195382 & 0.146981 & 0.086368 & 0.044627 & 0.0257549 & 0.0190941 & 0.0035524 \\
\hline Sargodha & 0.294974 & 0.267903 & 0.219154 & 0.13956 & 0.071398 & 0.0309534 & 0.0083046 & 0 \\
\hline Bhakkar & 0.406863 & 0.387032 & 0.345588 & 0.277406 & 0.198084 & 0.1156417 & 0.032754 & 0 \\
\hline Khushab & 0.347518 & 0.327128 & 0.272163 & 0.205674 & 0.136525 & 0.0689273 & 0.0316933 & 0.0053191 \\
\hline Mianwali & 0.346448 & 0.325764 & 0.264164 & 0.183228 & 0.101394 & 0.0676709 & 0.0191097 & 0.0017986 \\
\hline $\begin{array}{l}\text { Gunj } \\
\text { Town }\end{array}$ & 0.154128 & 0.115138 & 0.062385 & 0.019725 & 0.001376 & 0.0013761 & 0 & 0 \\
\hline Shalimar Town & 0.229555 & 0.199017 & 0.139493 & 0.057195 & 0.017857 & 0.0036232 & 0.0036232 & 0 \\
\hline $\begin{array}{l}\text { Allama Iqbal } \\
\text { Town }\end{array}$ & 0.198029 & 0.161738 & 0.11828 & 0.069893 & 0.027778 & 0.0098566 & 0.0031362 & 0 \\
\hline AzizBhatti Town & 0.233882 & 0.200658 & 0.148026 & 0.086842 & 0.046053 & 0.0148026 & 0.0069079 & 0 \\
\hline Nishtar Town & 0.237817 & 0.210283 & 0.159113 & 0.081628 & 0.028996 & 0.0119396 & 0.0017057 & 0 \\
\hline Ravi Town & 0.16109 & 0.124761 & 0.0674 & 0.030115 & 0.009082 & 0.0031071 & 0.001673 & 0 \\
\hline Cantt Town & 0.16899 & 0.131533 & 0.071429 & 0.021777 & 0.004355 & 0 & 0 & 0 \\
\hline
\end{tabular}

Table 3: Contribution of Each Dimension in Overall Mo

\begin{tabular}{lllllllll}
\hline Dimension & $\mathrm{K}=1$ & $\mathrm{~K}=2$ & $\mathrm{~K}=3$ & $\mathrm{~K}=4$ & $\mathrm{~K}=5$ & $\mathrm{~K}=6$ & $\mathrm{~K}=7$ & $\mathrm{~K}=8$ \\
\hline Education & 0.131233 & 0.12674956 & 0.124952 & 0.129049 & 0.123444 & 0.117469 & 0.131129 & 0.125 \\
Water & 0.023762 & 0.02355654 & 0.023872 & 0.026432 & 0.028962 & 0.032551 & 0.040542 & 0.125 \\
Room & 0.162269 & 0.16384402 & 0.158142 & 0.140075 & 0.121744 & 0.119011 & 0.130749 & 0.125 \\
Expenditure & 0.193943 & 0.19894287 & 0.196617 & 0.176778 & 0.157157 & 0.147108 & 0.139617 & 0.125 \\
Sanitation & 0.138645 & 0.14373939 & 0.151732 & 0.16444 & 0.163609 & 0.150991 & 0.140124 & 0.125 \\
Electricity & 0.056348 & 0.06066449 & 0.071279 & 0.093813 & 0.125767 & 0.145223 & 0.139871 & 0.125 \\
Land & 0.235304 & 0.21953294 & 0.199605 & 0.172554 & 0.150116 & 0.139855 & 0.137844 & 0.125 \\
Asset & 0.058498 & 0.06297026 & 0.073802 & 0.096859 & 0.129201 & 0.147793 & 0.140124 & 0.125 \\
\hline
\end{tabular}

